ISSN : 2252-3839 (Print)

ISSN : 2549-2403 (On Line)

DOI : $10.28989 /$ compiler.v8i2.499

http://ejournals.stta.ac.id/index.php/compiler/

\title{
ESTIMATION OF TIME VOTING IN ELECTIONS USING ARTIFICIAL NEURAL NETWORK
}

\author{
Nur Hidayati ${ }^{1)}$, Muhammad Fachrie ${ }^{2)}$, Adityo Permana Wibowo ${ }^{3)}$ \\ ${ }^{1}$ Program Studi Magister Teknologi Informasi \\ 2,3 Jurusan Teknik Informatika \\ ${ }^{1,2,3}$ Universitas Teknologi Yogyakarta \\ J1. Siliwangi (Ringroad Utara), Jombor, Sleman, D. I. Yogyakarta \\ Email: ${ }^{1}$ nur.hidayati@student.uty.ac.id, ${ }^{2}$ muhammad.fachrie@ staff.uty.ac.id, \\ 3 adityopw@staff.uty.ac.id
}

\begin{abstract}
Since the first election policy was enacted simultaneously, it does not mean that it does not have potential problems, instead it causes other problems, which require extra time and energy in doing recapitulation. Simultaneous elections consist of presidential elections, DPR elections, Provincial DPRDs, City / Regency DPRDs, DPD, the more they are elected, the more influential is the time of voting and the time of vote recapitulation. The longer the voting time is done by the voters, the longer the recapitulation time. The longer time of recapitulation results in the fatigue of KPPS members which triggers inaccurate work and prone to manipulation and fraud so that it can damage the quality of elections. This study aims to determine the estimated time needed for voting for ballots in elections using the Multilayer Perceptron Artificial Neural Network (ANN) approach. The resulting time estimate is based on the time of the voter in the voting booth. The results of this study indicate that ANN with the Multilayer Perceptron Algorithm can calculate the estimated time required for ballot balloting by producing the best combination of learning parameters with 4 hidden neurons, learning rate 0.001, and 2000 epoch iterations resulting in an RMSE value of 108,015 seconds.
\end{abstract}

Keyword: Estimation, Time, Election, Multilayer Perceptron

\section{Latar Belakang Masalah}

Pelaksanaan pemilu umum (Pemilu) menjadi indikator dalam sistem demokrasi karena rakyat dapat berpartisipasi dalam menentukan pilihan politiknya terhadap pemerintahan dan negaranya. Melalui pemilu rakyat bisa memilih para wakilnya untuk duduk dalam parlemen maupun struktur pemerintahan. Dalam sejarah perjalanan bangsa Indonesia pemilu menjadi upaya nyata dalam mewujudkan tegaknya demokrasi dan merealisasikan kedaulatan rakyat dengan prinsip jujur dan adil (jurdil) serta langsung, umum, bebas dan rahasia (luber)[1].

Ketika MK kemudian memutuskan untuk penyelenggaraan pemilu serentak, putusan MK masih belum putusan operasional yang menjawab kerisauan-kerisauan atas banyaknya penyelenggaraan pemilu di atas. Mungkin alasan agar tidak jenuh, bisa terjawab oleh pemilu serentak ini, juga mungkin soal efisiensi dalam penyelenggaraan[1].

Proses pemilihan pemimpin masyarakat selama ini dilakukan dengan cara manual mulai dari proses pemilihan sampai ke proses perhitungan suara. Cara ini membutuhkan sumber daya yang cukup banyak serta memiliki banyak celah kecurangan. Dengan menggunakan cara berbasis teknologi informasi, proses pemilihan pemimpin masyarakat akan menjadi lebih hemat sumber daya dan menutup beberapa celah kecurangan yang ada 
[2]. Dimensi utama aksesibilitas meliputi pelayanan dan perhatian terhadap pemilih disabilitas. Prinsip utamanya yaitu, bagaimana memastikan agar pemilih dapat mengakses TPS dengan tanpa hambatan saat memberikan suaranya pada hari pencoblosan[3].

Dalam penggunaan desain pemilu serentak, praktek yang banyak digunakan adalah penggabungan antara pemilihan eksekutif dengan pemilihan legislatif. Desain ini banyak digunakan di negara-negara Amerika Latin. Bukan hanya untuk tingkat nasional, pemilu serentak di beberapa negara juga dilakukan dengan menggabungkan antara pelaksanaan pemilu nasional dengan pemilu regional atau lokal[4].

Penyelenggaraan Pilpres dan Pileg secara serentak memang akan lebih efisien, sehingga pembiayaan penyelenggaraan lebih menghemat uang negara yang berasal dari pembayar pajak dan hasil eksploitasi sumber daya alam serta sumber daya ekonomi lainnya. Hal itu akan meningkatkan kemampuan negara untuk mencapai tujuan negara sebagaimana diamanatkan 253 VOL. 21 NO.2 DESEMBER 2014 dalam Pembukaan UUD 1945 yang antara lain untuk memajukan kesejahteraan umum dan sebesar-besarnya kemakmuran rakyat. Selain itu, Pilpres yang diselenggarakan secara serentak dengan Pileg juga akan mengurangi pemborosan waktu dan mengurangi konflik atau gesekan horizontal di masyarakat[5].

Berdasarkan permasalahan diatas, dengan adanya informasi mengenai estimasi waktu pencoblosan yang berbeda-beda dan adanya akibat yang ditimbulkan terkait lamanya waktu pencoblosan, maka peneliti mencoba untuk melakukan perhitungan estimasi waktu pencoblosan dengan menggunakan pendekatan Jaringan Syaraf Tiruan (JST).

Penelitian mengenai perhitungan estimasi waktu pernah dilakukan dengan menggunakan metode Instantaneous Model. Penelitian tersebut membahas tentang perhitungan estimasi waktu perjalanan kendaraan bermotor sehingga mendapatkan waktu yang bisa diandalkan. Data yang diproses berdasarkan kecepatan kendaraan yang dikumpulkan dari setiap link pada saat $k$. Waktu tempuh setiap link dihitung sebagai Panjang link dibagi dengan rata-rata kecepatan sesaat di hulu dan hilir link. Penelitian tersebut menunjukkan bahwa ruas jalan sejauh $7 \mathrm{KM}$ dengan menggunakan parameter kecepatan rata-rata waktu adalah 7,472 menit. Sedangkan menggunakan kecepatan ratarata ruang adalah 7,785 menit[6].

Penelitian yang membahas tentang perhitungan estimasi menggunakan JST pernah dilakukan. Penelitian tersebut membahas tentang perhitungan Needs Office Equipment (kebutuhan barang tidak habis pakai) menggunakan Algoritma Backpropagation pada setiap ruangan di Kantor Dinas Kebudayaan dan Pariwisata Provinsi Sumatera Barat. Penelitian tersebut menunjukkan bahwa JST dengan Algoritma Backpropagation bisa menghitung kebutuhan barang tidak habis pakai dengan prosentase $99 \%$. Untuk mencapai nilai akurasi tersebut dengan pola 5-9-1, nilai epoch 11 dan MSE 0.099069[7].

Penelitian lain yang menggunakan JST sudah banyak dilakukan, antara lain penggunaan JST untuk memprediksi kinerja satpam. Kinerja yang dihasilkan pada penelitian ini dibagi menjadi 3 yaitu kinerja baik, cukup, dan buruk. Penelitian tersebut menggunakan 175 record data dengan 10 atribut yang diolah menggunakan Multilayer Perceptron dan menggunakan Teknik Cross Validation dengan 10 fold. Menghasilkan nilai akurasi sebesar $97.75 \%[8]$.

Penelitian lain yang menggunakan JST juga pernah dilakukan untuk deteksi kanker payudara. Penelitian tersebut menggunakan dataset dari UCI Machine Learning dengan 10 atribut yang menjadi faktor penentu penyakit kanker payudara. Penelitian tersebut menggunakan arsitektur JST dengan 2 hidden layer dan menunjukkan bahwa dari 10 
atribut, hanya 4 atribut yang paling berpengaruh untuk mendeteksi penyakit Kanker Payudara. Dari 4 atribut tersebut menghasilkan nilai akurasi sebesar 80\%[9].

Penelitian ini bertujuan untuk membangun model yang mampu melakukan estimasi waktu yang digunakan oleh tiap pemilih di bilik suara. Hal ini dilakukan dengan mencatat terlebih dahulu profil setiap pemilih yang akan menggunakan hak pilihnya, kemudian mencatat durasi waktu yang dihabiskan oleh tiap pemilih di dalam bilik suara. Hasil pencatatan tersebut diolah menjadi data yang diperlukan untuk membangun model estimasi berbasis Jaringan Syaraf Tiruan (JST).

Dengan demikian, durasi waktu dari tiap pemilih dapat diprediksi berdasarkan profilnya masing-masing dan kebutuhan waktu dalam penyelenggaraan Pemilu dapat diprediksi, sehingga dapat diukur apakah tata laksana Pemilu tersebut realistis untuk dilakukan atau tidak.

\section{Metodologi Penelitian}

Penelitian ini dilakukan di TPS V Pedukuhan Jogonalan, Tirtorahayu, Galur, Kulon Progo. Untuk mencapai tujuan penelitian, langkah-langkah yang dilakukan, yakni akuisisi atau pengambilan data di lokasi yang telah dipilih, prapemrosesan data, dan pembangunan model estimasi waktu berbasi JST.

\subsection{Akuisisi Data}

Pengambilan data dilakukan pada tanggal 17 April 2019 di TPS V Pedukuhan Jogonalan, Tirtorahayu, Galur, Kabupaten Kulonprogo, D.I. Yogyakarta mulai dari saat TPS dibuka hingga waktu penutupan. Pencatatan dilakukan dengan menghitung durasi waktu yang digunakan oleh setiap pemilih selama berada di bilik suara. Dengan mempertimbangkan bahwa tahap yang paling menyita waktu selama proses pemungutan suara adalah ketika pemilih mencoblos kandidatnya di dalam bilik suara, maka penghitungan waktu dimulai ketika masing-masing pemilih masuk ke dalam bilik suara dan selesai ketika pemilih keluar dari bilik suara. Namun, karena keterbatasan sumber daya yang melakukan pencatatan waktu, maka tidak semua pemilih dapat dicatat lama waktunya.

Setelah itu, profil mengenai pemilih yang telah dicatat waktunya selama di bilik suara dikumpulkan melalui proses wawancara maupun dengan mengambil data yang tertera di Daftar Pemilih Tetap (DPT). Adapun komponen profil yang dicatat, yakni jenis kelamin, usia, pendidikan akhir, dan pekerjaan. Jenis kelamin dan usia dapat dengan mudah didapat melalui DPT yang ditempel di tiap TPS, sedangkan data mengenai pendidikan akhir dan pekerjaan diperoleh melalui proses wawancara. Proses akuisisi data ini berhasil mengumpulkan sebanyak 47 data pemilih.

\subsection{Pemrosesan Data}

Jumlah data keseluruhan yang digunakan 47 data. Pembagian data dilakukan dengan membagi sampel data menjadi dua bagian dengan teknik random sampling dengan proporsi pembagian sebanyak $70 \%$ untuk data latih dan $30 \%$ untuk data uji, sehingga dihasilkan sebanyak 33 data latih dan 14 data uji. Data latih terdiri atas 27 orang perempuan dan 30 orang laki-laki, sedangkan data uji terdiri dari 9 orang perempuan dan 5 orang laki-laki.

Pencatatan waktu selama pemilih berada di dalam bilik menggunakan satuan detik. Rata-rata usia peserta pemilu berkisar pada angka 40 tahun. Teknik penghitungan waktu yang digunakan saat pencoblosan untuk setiap pemilih dihitung dari mulai pada saat pemilih memasuki bilik kotak suara sampai melipat kartu suara. Jumlah atribut pada data 
sebanyak 5 buah yang terdiri dari atribut 'waktu selama di bilik', 'usia', 'jenis kelamin', 'pendidikan', dan 'pekerjaan'. Atribut 'waktu selama di bilik' berperan sebagai atribut target atau keluaran yang tipenya adalah bilangan kontinu (real), sedangkan atribut 'usia' bertipe bilangan bulat (integer), dan atribut 'jenis kelamin' dan 'pekerjaan' bertipe nominal/ kategorikal, di mana pada atribut 'jenis kelamin', angka ' 0 ' menyatakan 'lakilaki' dan angka ' 1 ' menyatakan 'perempuan'.

\subsection{Jaringan Syaraf Tiruan}

Jaringan Syaraf Tiruan (JST) merupakan salah satu representasi buatan dari otak yang selalu mencoba mensimulasikan proses pembelajaran pada otak manusia tersebut. Otak manusia berisi berjuta sel syaraf yang bertugas untuk memproses informasi. Setiap sel bekerja seperti suatu prosesor mendukung kemampuan kerja otak manusia (Setiawan, 2016).

Arsitektur JST memiliki beberapa lapisan yang terurut, yakni input layer, hidden layer, dan output layer. Di setiap lapisan tersebut terdapat sejumlah neuron yang berfungsi sebagai unit pemrosesan data yang saling terkoneksi dengan neuron-neuron pada lapisan di depannya. Gambar 1 mengilustrasikan arsitektur dari sebuah Multi Layer Perceptron (MLP) yang merupakan model JST yang paling populer dan memiliki kinerja yang sangat baik.

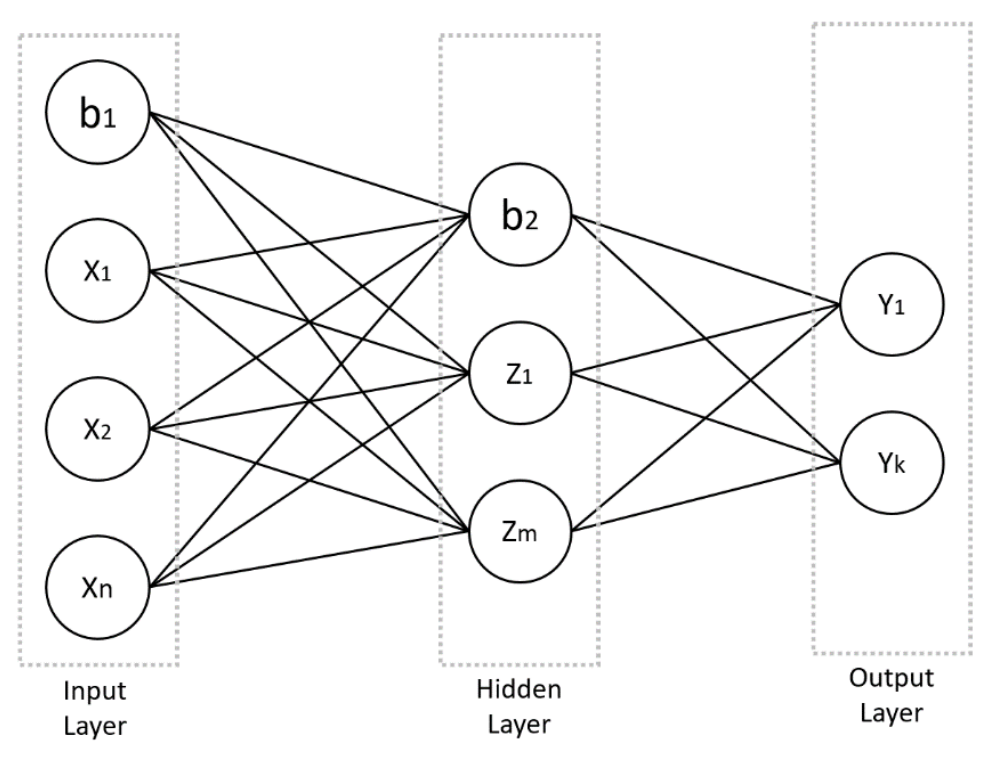

Gambar 1 Arsitektur Multi Layer Perceptron (MLP)

JST mampu mempelajari dan mengenali suatu pola berdasarkan pengetahuan yang ia dapatkan melalui proses pelatihan yang disebut learning algorithm. Setiap kali JST melakukan proses pelatihan, maka bobot-bobot jaringan (weights) yang menghubungkan neuron-neuron pada tiap lapisan akan diperbarui. Setiap neuron pada hidden layer dan output layer melakukan proses kalkulasi untuk mendapatkan output berupa nilai aktivasi menggunakan fungsi aktivasi sigmoid yang dirumuskan oleh persamaan (1).

$$
f(\text { net })=\frac{1}{1+\exp ^{- \text {net }}}
$$


dimana,

$$
\text { net }=\sum_{i=1}^{n} x_{i}, w_{i j}+b_{i}
$$

$x$ adalah vektor input, $w$ adalah vektor bobot yang menghubungkan dua lapisan, dan $b$ adalah nilai bias. Proses penghitungan tersebut dilakukan secara bertahap, yakni dimulai dari menghitung nilai aktivasi dari setiap neuron pada hidden layer, kemudian nilai tersebut dijadikan input untuk proses kalkulasi nilai aktivasi pada output layer.

\section{$2.4 \quad$ Root Mean Square Error}

Root Mean Square Error (RMSE) merupakan salah satu parameter yang biasa digunakan sebagai indikator untuk pengolahan pola, baik itu pola citra digital maupun pola text[10]. Pada penelitian ini perhitungan RMSE digunakan untuk mencari selisih estimasi waktu yang dihasilkan untuk pencoblosan surat suara di bilik suara. Untuk menghitung RMSE digunakan persamaan (3).

$$
R M S E=\sqrt{\frac{1}{m \times n} \sum_{i=0}^{n-1} \sum_{j=0}^{m-1}[f(i, j)-g(i, j)]^{2}}
$$

\section{Hasil dan Pembahasan}

Pengujian model dilakukan dengan menggunakan aplikasi Rapidminer versi 9.2 yang terkenal sangat baik dalam melakukan aktivitas Data Mining maupun Machine Learning.

Komponen yang digunakan pada Rapidminer untuk pengolahan dataset terdiri dari Read Excel yang digunakan untuk membaca dataset dengan file .xls, kemudian dihubungkan dengan komponen Nominal to Numerical yang digunakan untuk mengkonversi tipe data dataset ke numerik. Selanjutnya digunakan komponen Split Data yang digunakan untuk membagi dataset menjadi data uji dan data latih. Komponen Neural Net digunakan untuk metode yang digunakan, yaitu Neural Network atau Jaringan Syaraf Tiruan. Terakhir, dihubungkan dengan komponen Apply Model dan Performance untuk menghasilkan nilai akurasi dan pemodelan arsitektur JSTnya. Komponen yang digunakan untuk pemodelan data estimasi pada rapidminer seperti terlihat pada gambar 2.

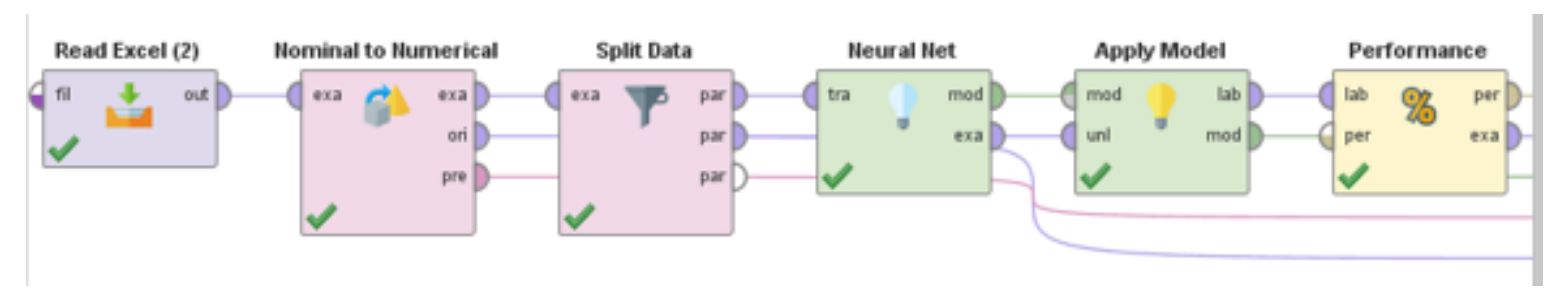

Gambar 2. Model Estimasi Rapidminer 
Dari data yang diperoleh dari TPS kemudian diolah dengan Rapidminer menggunakan tiga skenario dengan nilai parameter learning yang berbeda-beda. Pengolahan tersebut menunjukkan hasil seperti yang terlihat pada Tabel 1 .

Tabel 1. Proses Design Hidden Layers

\begin{tabular}{|c|c|c|c|c|}
\hline No & $\begin{array}{c}\text { Jumlah Hidden } \\
\text { Neuron }\end{array}$ & Learning & Epoch & RMSE \\
\hline 1 & 4 & 0,001 & 2000 & 108.015 \\
\hline 2 & 2 & 00.01 & 1500 & 157.235 \\
\hline 3 & 3 & 00.01 & 1000 & 191.259 \\
\hline
\end{tabular}

Dari hasil diatas dapat diambil kesimpulan bahwa nilai akurasi yang terbaik adalah nomor 1 dengan jumlah hidden neuron 4, learning 0,001, epoch 2000, dengan nilai Root Mean Squared Error (RMSE) sebesar 108.015 detik.

\section{Kesimpulan}

Penelitian ini berhasil menunjukkan bahwa JST dengan Algoritma Multiperceptron berhasil digunakan untuk estimasi waktu pencoblosan tiap pemilih dibilik suara. Terbukti dengan menghasilkan kombinasi parameter learning terbaik dengan 4 hidden neuron, learning rate 0.001 , dan iterasi sebanyak 2000 epoch menghasilkan nilai RMSE sebesar 108.015 detik. Terlihat bahwa, nilai RMSE tersebut cukup kecil, meskipun data latih yang digunakan hanya sedikit. Pada hasil penelitian terlihat pula bahwa kombinasi learning rate yang lebih kecil dan jumlah iterasi yang lebih banyak cenderung memberikan kinerja yang lebih baik.

\section{Daftar Pustaka}

[1] Triono. (2017). Menakar Efektivitas Pemilu Serentak 2019. Jurnal Wacana Politik, 2(2), 156-164.

[2] Prayogo, Y. P., Wintolo, H., \& Indrianingsih, Y. (2013). Perancangan dan Penerapan Algoritma Nakula Sadewa untuk Mengatasi Duplikasi Pemilihan di tempat Pemungutan Suara. Jurnal Compiler, 2(2), 1-20.

[3] Agustyati, K. (2016). Syarat Kepesertaan Peserta Pemilu. Jurnal Pemilu Dan Demokrasi, 9(9), 1-17.

[4] Solihah, R. (2018). Peluang dan Tantangan Pemilu Serentak 2019 dalam Perspektif Politik. Jurnal Ilmiah Ilmu Pemerintahan, 3(1), 73-88. https://doi.org/10.14710/jiip.v3i1.3234

[5] Prasetyoningsih, N. (2014). Dampak Pemilihan Umum Serentak Bagi Pembangunan Demokrasi Indonesia. Jurnal Media Hukum, 21(2), 241-263.

[6] Haqqi, R., Marpaung, H. S., \& Sebayang, M. (2017). Analisis Waktu Tempuh Kendaraan Bermotor dengan Metode Estimasi Instantaneous Model. Jurnal JOM FTEKNIK, 4(2), 1-8.

[7] Setiawan, D. (2016). Penerapan Jaringan Syaraf Tiruan Untuk Estimasi Needs Office Equipment Menggunakan Algoritma Backpropagation. Jurnal Sains Dan Teknologi Informasi, 2(1), 2-6.

[8] Fachrie, M., \& Wibowo, A. P. (2018). Jaringan syaraf tiruan untuk memprediksi kinerja satpam. Jurnal Informatika Dan Komputer, 3(1), 46-51. 
[9] Wibisono, G., \& Hermawan, A. (2019). Faktor-Faktor Penentu Gejala Penyakit Kanker Payudara. Jurnal Aplikasi Sains, Informasi, Elektronika Dan Komputer, 1(1), 1-6. Retrieved from http://jurnal.unmer.ac.id/index.php/jasiek/article/view/3098/pdf

[10] Pamungkas, A. (2017). Cara Menghitung Nilai MSE, RMSE, dan PNSR pada Citra Digital. Retrieved July 14, 2019, from https://pemrogramanmatlab.com/2017/06/04/cara-menghitung-nilai-mse-rmse-danpsnr-pada-citra-digital/

[11] Waluyo, T., Hermawan, A., \& Wibowo, A. P. (2019). Prediksi Penjualan Sepeda Motor Honda Menggunakan Jaringan Syaraf Tiruan. Jurnal of Information System Management, 1(1), 31-35. 
Nur Hidayati, Muhammad Fachrie, Adityo Permana Wibowo 